\title{
Effects of Cervico-Mandibular Manual Therapy in Patients with Temporomandibular Pain Disorders and Associated Somatic Tinnitus: A Randomized Clinical Trial
}

\author{
Pablo Delgado de la Serna, PT, MSc, * Gustavo Plaza-Manzano, PT, PhD, ${ }^{t, \neq}$ Joshua Cleland, PT, PhD, ${ }^{\S, \pi}, \|$ \\ César Fernández-de-las-Peñas, PT, PhD, ${ }^{\|, * *}$ Patricia Martín-Casas, PT, ${ }^{\prime}{ }^{\prime}{ }^{\dagger}{ }^{\dagger}$ and \\ María José Díaz-Arribas, $\mathrm{PT}, \mathrm{PhD}^{\dagger}$
}

\begin{abstract}
*Department of Physical Therapy, Universidad Francisco de Vitoria, Madrid, Spain; ${ }^{\dagger}$ Department of Radiology, Rehabilitation and Physiotherapy, Universidad Complutense de Madrid, Madrid, Spain; ${ }^{\ddagger}$ Instituto de Investigación Sanitaria del Hospital Clínico San Carlos, Madrid, Spain; ${ }^{\S}$ Physical Therapist, Rehabilitation Services, Concord Hospital, Concord, New Hampshire; "Faculty, Manual Therapy Fellowship Program, Regis University, Denver, Colorado; "Department of Physical Therapy, Franklin Pierce University, Manchester, New Hampshire, USA; "Department of Physical Therapy, Occupational Therapy, Rehabilitation and Physical Medicine, Universidad Rey Juan Carlos, Alcorcón, Madrid, Spain; ${ }^{*}$ Cátedra de Investigación y Docencia en Fisioterapia: Terapia Manual y Punción Seca, Universidad Rey Juan Carlos, Alcorcón, Madrid, Spain
\end{abstract}

Correspondence to: César Fernández-de-las-Peñas, PT, PhD, Facultad de Ciencias de la Salud, Universidad Rey Juan Carlos, Avenida de Atenas s/n, 28922 Alcorcón, Madrid, Spain. Tel: + 349148888 84; Fax: + 349148889 57; E-mail: cesar.fernandez@urjc.es.

Disclosure and conflicts of interest: Financial disclosure statements have been obtained, and no conflicts of interest have been reported by the authors or by any individuals in control of the content of this article. No conflicts of interest are declared.

Trial registration: ClinicalTrials.gov, NCT02850055 (http://www.clinicaltrials.gov).

\begin{abstract}
Objective. This randomized clinical trial investigated the effects of adding cervico-mandibular manual therapies into an exercise and educational program on clinical outcomes in individuals with tinnitus associated with temporomandibular disorders (TMDs). Methods. Sixty-one patients with tinnitus attributed to TMD were randomized into the physiotherapy and manual therapy group or physiotherapy alone group. All patients received six sessions of physiotherapy treatment including cranio-cervical and temporomandibular joint (TMJ) exercises, self-massage, and patient education for a period of one month. Patients allocated to the manual therapy group also received cervicomandibular manual therapies targeting the TMJ and cervical and masticatory muscles. Primary outcomes included TMD pain intensity and tinnitus severity. Secondary outcomes included tinnitus-related handicap (Tinnitus Handicap Inventory [THI]), TMD-related disability (Craniofacial Pain and Disability Inventory [CF-PDI]), self-rated quality of life (12-item Short Form Health Survey [SF-12]), depressive symptoms (Beck Depression Inventory [BDI-II]), pressure pain thresholds (PPTs), and mandibular range of motion. Patients were assessed at baseline, one week, three months, and six months after intervention by a blinded assessor. Results. The adjusted analyses showed better outcomes (all, $P<0.001$ ) in the exercise/education plus manual therapy group (large effect sizes) for TMD pain ( $\eta 2 P=$ 0.153 ), tinnitus severity ( $\eta 2 P=0.233)$, THI ( $22 P=0.501)$, CF-PDI ( $2 P=0.395)$, BDI-II $(\eta 2 P=0.194)$, PPTs $(0.363$ $<\eta 2 P<0.415)$, and range of motion ( $2 P=0.350)$, but similar changes for the SF-12 $(P=0.622, \eta 2 P=0.01)$ as the exercise/education alone group. Conclusions. This clinical trial found that application of cervico-mandibular manual therapies in combination with exercise and education resulted in better outcomes than application of exercise/ education alone in individuals with tinnitus attributed to TMD.
\end{abstract}

Key Words: Tinnitus; Temporomandibular Pain; Physical Therapy; Manual Therapy; Pain 


\section{Introduction}

Temporomandibular disorder (TMD) is an umbrella term used to describe a myriad of symptoms including masticatory muscle pain and joint-associated symptoms (degenerative joint disease and capsulitis) [1]. Pain is the most common and limiting feature of TMD, but it can be also accompanied by decreased mobility of the mouth, headaches, stiffness, or fatigue, all of which impact the quality of life of patients. It has been reported that $\sim 75 \%$ of the general population will experience TMDassociated symptoms at some point during their life [2]. Köhler et al. [3] found that the prevalence of TMD signs and number of treatments as a result of TMD pain have increased during the last decades. In fact, a recent study observed that orofacial pain and TMD are associated with a substantial burden and impact on society [4].

Another common associated symptom experienced by individuals with TMD is tinnitus. Tinnitus or "ringing in the ears" is described as the subjective perception of sound without any external stimulation [5]. Tinnitus and TMD occur most frequently in the fifth decade of life and are more prevalent in females than in males (female:male ratio $=3: 2$ ) [6]. In fact, it has been reported that subjects with TMD are more likely to develop tinnitus than those without TMD [7], and vice versa, people with tinnitus are also more likely to develop TMD-associated symptoms [8]. Tinnitus elicited by the somatosensory system of the temporomandibular joint (TMJ), the masticatory muscles of the neck, is referred to as "somatic tinnitus," which is present in $36-43 \%$ of individuals with subjective tinnitus [5].

Physical therapy can be used for the management of TMD-associated symptoms and for somatic tinnitus. Two recent meta-analyses support the use of manual therapy and exercises for TMD pain symptoms; however, no consensus exists on which therapeutic approach is the most effective $[9,10]$. Similarly, a recent systematic review identified preliminary evidence for physical therapy in the management of subjective tinnitus, although the quality of the identified trials was low [11]. This review included two studies investigating TMJ treatment, for example, occlusal bite splints or adjustments, laser, and jaw exercises [11]. Buergers et al. [12] also reported that patients with TMD-associated tinnitus who received oral splints and physiotherapy experienced positive outcomes; however, no control group was included in this study. To date, no randomized clinical trial has examined the effects of manual therapies targeting the TMJ and cervical spine on individuals with TMD and tinnitus. Therefore, the aim of this clinical trial was to evaluate the effectiveness of adding specific cervico-mandibular manual therapies into an exercise and educational program on clinical outcomes in people with tinnitus associated with TMD. We hypothesized that individuals receiving cervico-mandibular manual therapies in addition to the exercise and educational program will experience better outcomes than those who only receive an exercise and educational program.

\section{Methods}

\section{Study Design}

A randomized, parallel-group, multicenter clinical trial was conducted to compare the effects of the inclusion of cervico-mandibular manual therapies into an exercise and educational program in patients with tinnitus associated with TMD. The study design was approved by the Institutional Review Board of Universidad Complutense de Madrid, Spain (16/477-E), and the study was prospectively registered (ClinicalTrials.gov: NCT02850055). This report follows the Consolidated Standards of Reporting Trials (CONSORT) extension for clinical trials [13].

\section{Participants}

Between January 2017 and December 2017, consecutive patients with tinnitus concomitant with TMD presenting at to one of three private physiotherapy clinics were screened for eligibility criteria. The inclusion criteria were 1) age 18-65 years and 2) diagnosis of tinnitus attributed to TMD; that is, they had to report self-reported tinnitus symptoms and have a diagnosis of TMD according to the Research Diagnostic Criteria for TMD [14]. The following symptoms were assessed using the RDC/ TMD criteria: location of pain, jaw range of motion and associated joint pain, clicking sounds, and pain upon muscle and joint palpation. To be considered tinnitus attributed to TMD, an association between both disorders had to be reported by the patient [15]. Most patients associated their tinnitus with TMJ use, for example, during eating.

The exclusion criteria included 1) diagnosis of ear, nose, and throat medical pathology underlying the tinnitus; 2 ) neurological problems that could potentially cause the tinnitus; 3) inability to read, understand, and complete the questionnaires or understand and follow commands (e.g., illiteracy, dementia, or blindness); 4) comorbid fibromyalgia syndrome; 5) had received physiotherapy or other treatment in the head/neck in the last 12 months; or 6) any contraindication to physical therapy as noted in the patient's Medical Screening Questionnaire (i.e., tumor, fracture, rheumatoid arthritis, osteoporosis, prolonged history of steroid use, etc.). A detailed medical exam including an ear-nose-throat (ENT) exam was performed in all participants. All subjects signed an informed consent before participation in the study.

\section{Randomization and Masking}

Once the baseline assessment was completed, patients were randomly assigned to receive either physical therapy plus manual therapy or physical therapy alone. 
Concealed allocation was performed by an external researcher not involved in subject recruitment using a computer-generated randomized table of numbers created for each participating site before the beginning of the study. The group assignment was recorded on an index card. This card was folded in half, such that the label with the patient's group assignment was on the inside of the fold. The folded index card was then placed inside the envelope, and the envelope was sealed. A second therapist blinded to the baseline examination findings opened the envelope and proceeded with treatment according to the group assignment.

\section{Treatment Interventions}

All interventions were applied by a physical therapist with more than 10 years of experience in the management of patients with TMD. Both groups received six treatment sessions, two sessions the first week and four weekly sessions to complete the treatment in a month, of multimodal physiotherapy treatment of 30 minutes' duration. The intervention included a cranio-cervical and TMJ exercise program, self-massage of the masticatory muscles (masseter and temporalis), and patient education $[9,16]$.

The exercise therapy program consisted of a mixed approach including mobility, postural education, and motor control exercises of the TMJ, the tongue, and the neck; instructions for resting jaw position, head/neck position, and posture were provided [9]. Patients were asked to perform the exercises twice per day during the intervention period. Patients recorded in a diary their adherence to the exercise program during the study period. Therapeutic patient education included a brief description of the neurophysiological mechanism of pain, active coping strategies, distraction strategies, changing behaviors about pain, and correction of inappropriate behaviors of the TMJ, such as tongue parafunctions. All participants received a self-care book for home.

Patients allocated to the cervico-mandibular manual therapy group also received manual therapy techniques focusing on the TMJ and the masticatory and cervical musculature during the treatment sessions. Participants received an oscillatory TMJ inferior glide accessory mobilization of mandible distraction intervention (Figure 1) for 90 seconds. In addition, different manual therapies including pressure release, soft tissue mobilization, or longitudinal strokes of the following cranio-cervical musculature were applied: masseter (Figure 2), temporalis (Figure 3), sternocleidomastoid (Figure 4), and upper trapezius (Figure 5). These muscles were chosen because their pain referral is perceived around the TMJ, the ear, or the orofacial area and can contribute to tinnitus [17-19].

\section{Outcome Measures}

All outcomes were assessed at baseline, one week after the treatment program, and three and six months after

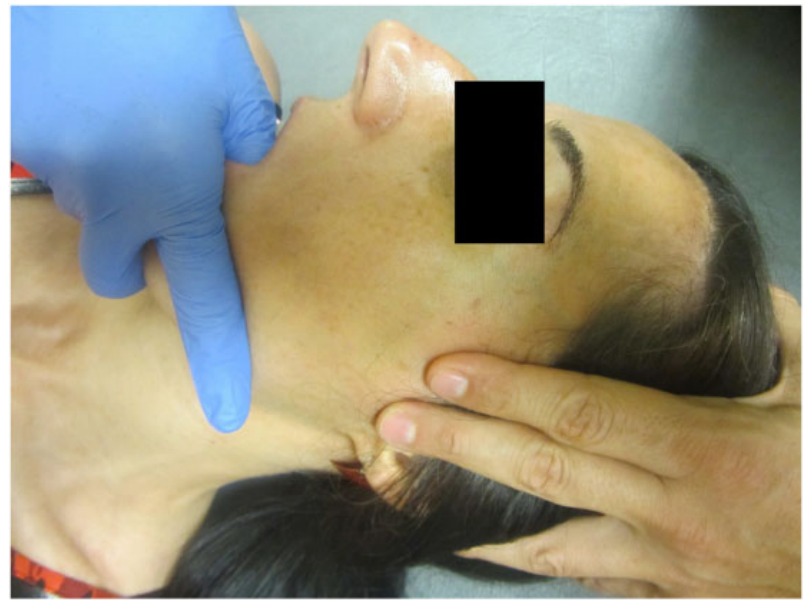

Figure 1. Inferior glide accessory mobilization of the temporomandibular joint.

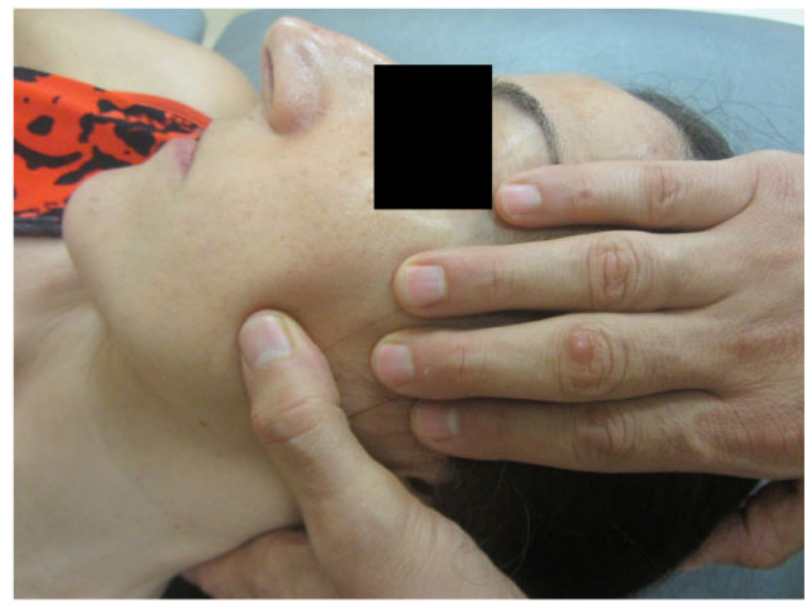

Figure 2. Soft tissue mobilization of the masseter muscle.

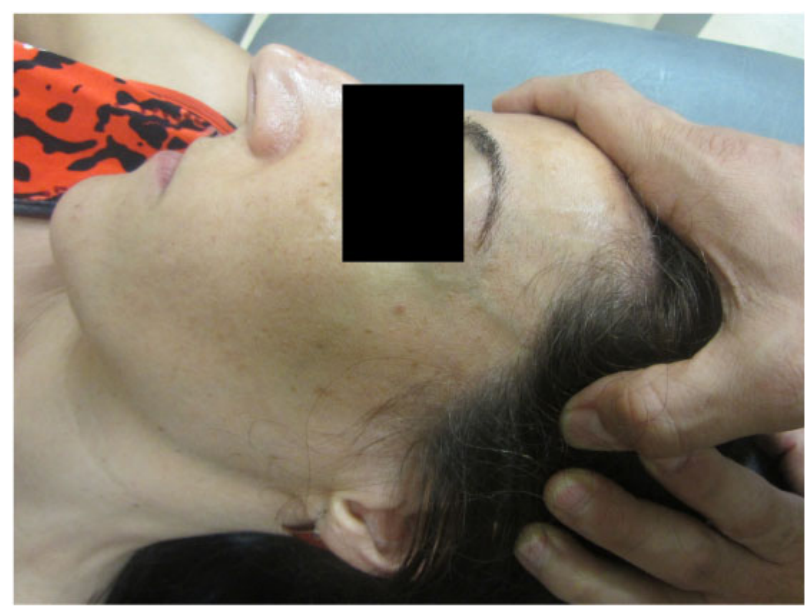

Figure 3. Soft tissue mobilization of the temporalis muscle.

the last treatment session by an assessor blinded to group allocation.

The primary outcomes were the intensity of TMD (NPRS) and the severity of the tinnitus, assessed by 


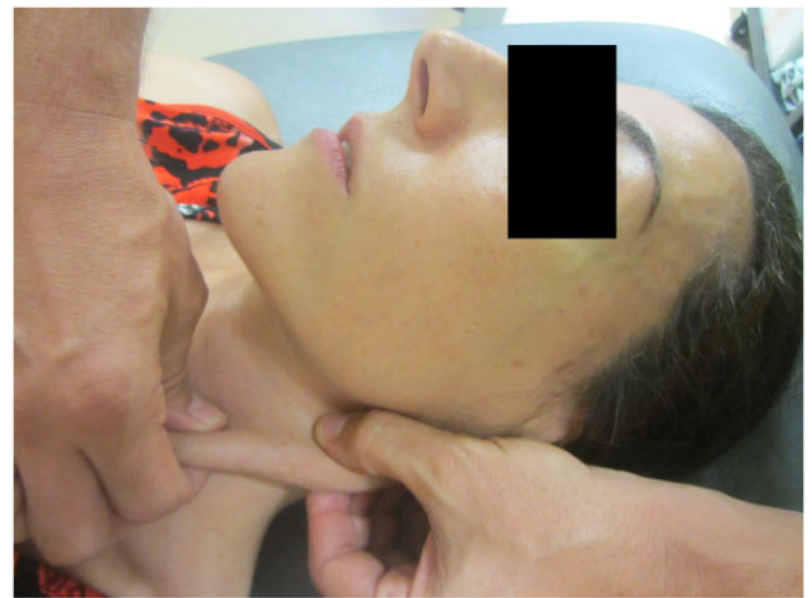

Figure 4. Soft tissue mobilization of the sternocleidomastoid muscle.

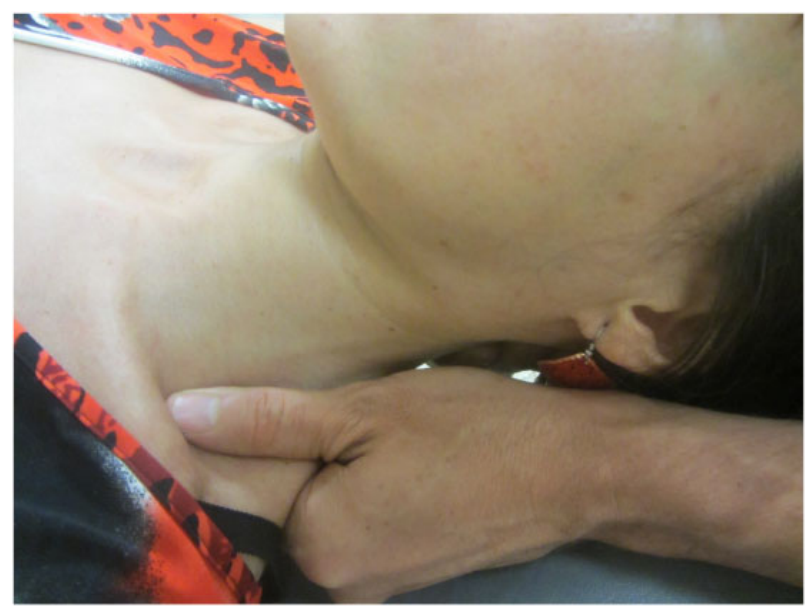

Figure 5. Soft tissue mobilization of the upper trapezius muscle.

tinnitus annoyance and tinnitus loudness (VAS). As patients included in this trial exhibited TMJ pain and tinnitus, both symptoms were assessed separately. Participants rated their intensity of TMD pain at rest on a numerical pain rating scale (NPRS; $0=$ no pain, $10=$ maximum pain) [20]. As there has not been an identified minimum clinically important difference (MCID) for NPRS in patients with TMD, we set the MCID at a predetermined reduction of two points [21] or a change of $30 \%$ of the initial score [22]. The visual analog scale (VAS) was used to assess tinnitus severity (tinnitus annoyance and tinnitus loudness). The VAS scale consisted of a $10-\mathrm{mm}$ line with marked end points with two faces drawn: a smiling one indicating lack of annoyance/no perception of tinnitus (painted under the left end point of a line) and a sad one indicating extreme annoyance or extremely loud tinnitus (painted under the right end point of a line) [23]. The use of a VAS for assessing these subjective symptoms of tinnitus has been shown to have good reliability and validity. The estimated MCID ranged from 10 to $15 \mathrm{~mm}$ [23]. It has been also found that the combined VAS of both symptoms is more reliable than the isolated scales; therefore, in the current trial, the mean of both VAS scores was used in the main analysis [23].

Secondary outcomes included tinnitus-related handicap (Tinnitus Handicap Inventory [THI]) [24], TMDrelated disability (Craniofacial Pain and Disability Inventory [CF-PDI]) [25], general health-related quality of life (12-item Short Form Health Survey [SF-12]) [26], depressive symptom (Beck Depression Inventory [BDIII]) [27], pressure pain sensitivity (pressure pain thresholds [PPTs]), and mandibular range of motion.

The THI is a self-reported measure assessing the impact that tinnitus has on daily life and consists of 25 items divided into three scales: functional ( 11 items), catastrophic (five items), and emotional (nine items) [28]. There are three possible answers to each item: "yes" (four points), "sometimes" (two points), and "no" $(0$ points). Although each subscale can be scored independently, it has been proposed to report a total score (range $=0-100$ points) [29]. Fackrell et al. [30] proposed that a reduction of 20 or more points of the total score of the THI could be considered a clinically meaningful change.

The CF-PDI is a self-administered questionnaire designed to determine pain, disability, and functional status of the mandibular/craniofacial regions [25]. This questionnaire consists of 21 items with a total score ranging from 0 to 63 points, where higher values represent worse functional status. The CF-PDI questionnaire has good internal consistency, reproducibility, and construct validity. It has been reported that a score of 7 can be considered the minimal detectable change for this questionnaire [25].

The 12-item Short Form Health Survey (SF-12) is a generic health rating short version scale of the SF-36 questionnaire [26]. This questionnaire includes 12 questions from the original scales of the SF-36. Response categories for the items vary from two- to six-point scales, and raw scores for items range from 1 to 6 . After recoding raw scores for some items, the raw scores are transformed to provide a total score ranging from 0 (the worst healthrelated quality of life) to 100 (the best health-related quality of life) [26].

Patients completed the BDI-II for reporting their level of depressive symptoms. The BDI-II is 21-item self-report questionnaire assessing different aspects of depression, such as affective, cognitive, and somatic symptoms [27]. The BDI-II is easily adapted in most pain conditions for detecting depressive symptoms [31].

Pressure pain sensitivity was assessed by determining pressure pain thresholds (PPT), that is, the minimal amount of pressure applied on a point for the pressure sensation to first change to pain [32], bilaterally over the masseter and temporalis muscles and over the lateral aspect of the TMJ (anatomical projection of the lateral pterygoid muscle). A digital pressure algometer $\left(\mathrm{kg} / \mathrm{cm}^{2}\right)$ 


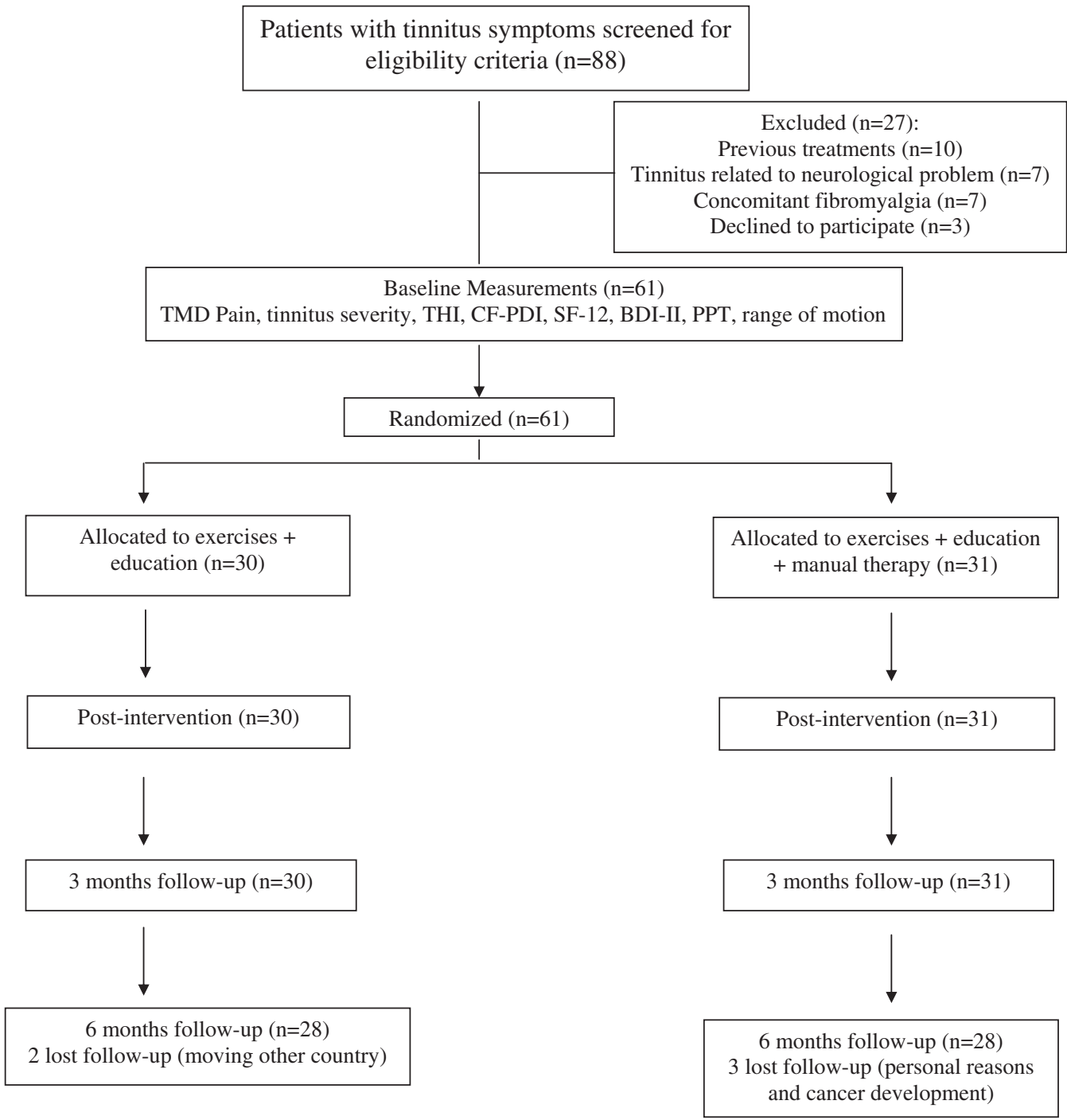

Figure 6. Flow diagram of patients throughout the course of the study.

was used to assess PPTs. All participants were instructed to press the switch when the sensation first changed from pressure to pain. The mean of three trials was calculated on each point and used for the main analysis. A 30 -second resting period was allowed between each measure. The reliability of pressure algometry in the masticatory structures has been found to be high in both healthy volunteers [33] and in patients with TMD [34]. As no side-to-side differences were observed, the mean of both sides on each muscle was considered for the analysis. The order of assessment was randomized between subjects.

Mandibular range of motion (maximal mouth opening and lateral excursions) was evaluated with a plastic device permitting the assessment of mouth movements in millimeters. This procedure has exhibited good intraand inter-rater reliability [35]. The minimal detectable change has been determined to be $6 \mathrm{~mm}$ for maximal mouth opening [36] and $1.8 \mathrm{~mm}$ for the rest of mouth movements [35].

\section{Treatment Side Effects}

Patients were asked to report any adverse event that they experienced during the study. In the current study, an adverse event was defined as sequelae of one week's duration with any symptom perceived as distressing and unacceptable to the patient and that required further treatment [37].

\section{Sample Size Determination}

The sample size was calculated using Ene 3.0 software (Autonomic University of Barcelona, Barcelona, Spain). The calculation was based on detecting between-groups differences of $10 \mathrm{~mm}$ on the VAS after treatment, assuming a standard deviation of $12 \mathrm{~mm}$ [23], a two-tailed test, an alpha level $(\alpha)$ of 0.05 , and a desired power $(\beta)$ of $80 \%$. The estimated desired sample size was calculated to be 25 subjects per group. A dropout rate of $20 \%$ was expected, so 30 participants were included on each group at baseline. 


\section{Statistical Analysis}

Data were analyzed using the SPSS, version 22.0 (SPSS Inc, Chicago, IL, USA), program and were conducted according to the intention-to-treat analysis. Means, standard deviations, and $95 \%$ confidence intervals were calculated for each variable. The Kolmogorov-Smirnov test revealed a normal distribution of all quantitative data $(P$ $>0.005)$. Baseline demographic and clinical variables between groups were compared using the independent $t$ test for continuous data and chi-square tests of independence for categorical data. A $4 \times 2$ analysis of covariance (ANCOVA) with time (before, immediately after, three months after, and six months after) as the within-subjects factor, group (exercise/education alone or exercise/education plus manual therapy) as the between-subjects factor, gender and center as covariates, and adjusted for baseline data was used to examine the effects of interventions on TMD pain, tinnitus severity, THI, CF-PDI, SF-12, BDIII, PPTs, and mandibular range of motion. Separate ANCOVAs were performed for each outcome. The main hypothesis of interest was the group * time interaction with a Bonferroni-corrected alpha of 0.017 (three moments). The effect size was calculated when the partial Eta squared $(\eta 2 \mathrm{p})$ was statistically significant. A Partial Eta squared of 0.01 was considered small, 0.06 medium, and 0.14 large [38].

\section{Results}

Eighty-eight consecutive subjects with self-reported tinnitus symptoms were screened for potential eligibility between January and December 2017. Sixty-one patients satisfied all criteria, agreed to participate, and were randomly allocated to exercise and education $(\mathrm{N}=30)$ or exercise and education plus manual therapy $(\mathrm{N}=31)$. The reasons for ineligibility are listed in the flow diagram of patient recruitment and retention (Figure 6). Baseline features between groups were similar for all outcomes (Table 1). None of the subjects receiving exercise and education with/without cervico-mandibular manual therapy reported any adverse events. In addition, patients reported an adherence of $97 \%$ to the exercise program during the treatment period.

\section{Primary Pain Outcomes}

The ANCOVA revealed significant group time * interactions for TMD pain $(\mathrm{F}=10.639, P<0.001, \eta 2 \mathrm{p}=$ $0.153)$ and tinnitus severity $(\mathrm{F}=17.878, P<0.001, \eta$ $2 \mathrm{p}=0.233)$ : Patients receiving exercise/education plus manual therapy exhibited a greater decrease (large effect sizes) in both outcomes than those receiving exercise/education alone (Table 2, Figure 7). Gender did not influence the effect in the main analysis (TMD pain: $\mathrm{F}=0.509, \quad P=0.478 ;$ tinnitus: $\mathrm{F}=0.475$, $P=0.493)$.
Table 1. Baseline characteristics by treatment assignment

\begin{tabular}{|c|c|c|}
\hline Baseline Variable & $\begin{array}{l}\text { Exercise }+ \\
\text { Education } \\
(\mathrm{N}=30)\end{array}$ & $\begin{array}{l}\text { Exercise }+ \\
\text { Education }+ \\
\text { Manual } \\
\text { Therapy } \\
(\mathrm{N}=31)\end{array}$ \\
\hline Gender (male/female) & $13 / 17$ & $12 / 19$ \\
\hline Age, y & $44.0 \pm 10.5$ & $42.5 \pm 12.0$ \\
\hline Months with tinnitus symptoms & $17.1 \pm 5.0$ & $17.5 \pm 6.5$ \\
\hline Intensity of TMD pain (NPRS, 0-10) & $5.2 \pm 1.7$ & $5.2 \pm 2.2$ \\
\hline Tinnitus severity (VAS, $0-10$ ) & $6.7 \pm 1.2$ & $6.8 \pm 1.2$ \\
\hline Tinnitus Handicap Inventory $(0-100)$ & $34.2 \pm 11.9$ & $36.1 \pm 9.5$ \\
\hline $\begin{array}{l}\text { Craniofacial Pain and } \\
\text { Disability Inventory (0-63) }\end{array}$ & $38.6 \pm 5.5$ & $40.7 \pm 8.2$ \\
\hline 12-item Short Form Health Survey $(0-100)$ & $31.3 \pm 3.4$ & $30.0 \pm 3.6$ \\
\hline Beck Depression Inventory (0-63) & $6.5 \pm 7.3$ & $7.4 \pm 5.4$ \\
\hline \multicolumn{3}{|l|}{ Mandibular range of motion, $\mathrm{mm}$} \\
\hline Maximal mouth opening & $31.5 \pm 3.2$ & $30.5 \pm 3.2$ \\
\hline Right lateral excursion & $5.9 \pm 0.7$ & $5.8 \pm 0.8$ \\
\hline Left lateral excursion & $5.9 \pm 0.6$ & $5.7 \pm 0.7$ \\
\hline \multicolumn{3}{|l|}{ Pressure pain thresholds, $\mathrm{kg} / \mathrm{cm} 2$} \\
\hline Masseter muscle & $2.2 \pm 0.4$ & $2.1 \pm 0.3$ \\
\hline Temporalis muscle & $2.3 \pm 0.4$ & $2.2 \pm 0.3$ \\
\hline TMJ area & $2.2 \pm 0.4$ & $2.3 \pm 0.4$ \\
\hline
\end{tabular}

Data are mean $(\mathrm{SD})$, except for gender.

NPRS = numeric pain rating scale (0-10; lower scores indicate less pain); $\mathrm{TMD}=$ temporomandibular disorder; $\mathrm{TMJ}=$ temporomandibular joint; VAS $=$ visual analog scale $(0-10$; lower scores indicate less pain).

\section{Tinnitus and TMD-Related Disability Outcomes}

The ANCOVA revealed significant group * time interactions for THI $(\mathrm{F}=39.291, P<0.001, \eta 2 \mathrm{p}=0.501)$ and CF-PDI $(\mathrm{F}=18.096, P<0.001, \eta 2 \mathrm{p}=0.395)$ : Subjects receiving exercise/education plus manual therapy exhibited greater improvements (large effect sizes) in tinnitus and TMD-related disability than those receiving exercise and education alone (Tables 2 and 3 ). Gender did not influence the effect in the main analysis (THI: $\quad \mathrm{F}=0.142, \quad P=0.707 ; \quad \mathrm{CF}-\mathrm{PDI}: \quad \mathrm{F}=0.018$, $P=0.895)$.

\section{Health-Related Quality of Life and Depressive Symptoms}

The results did not reveal a significant group * time interaction for health-related quality of life (SF-12: $\mathrm{F}=0.590$, $P=0.622, \eta 2 \mathrm{p}=0.01$ ): Patients in both groups experienced similar changes (small effect size) in quality of life (Table 3). A significant group * time interaction for depressive symptoms (BDI-II: $\mathrm{F}=14.234, P<0.001$, $\eta 2 \mathrm{p}$ $=0.194)$ was observed: Individuals receiving exercise and education plus manual therapy exhibited a greater decrease (large effect size) in depressive symptoms than those receiving exercise/education alone (Table 3). Gender did not influence the main effect in the analysis (SF-12: $\quad \mathrm{F}=0.586, \quad P=0.447 ; \quad \mathrm{BDI}-\mathrm{II}: \quad \mathrm{F}=0.469$, $P=0.496)$. 
Table 2. Pain intensity and tinnitus outcomes at baseline, postintervention, three months, and six months after treatment, as well as within-group and between-group mean scores by randomized treatment assignment

\begin{tabular}{|c|c|c|c|}
\hline \multirow[b]{3}{*}{ Outcomes } & \multicolumn{2}{|c|}{ Timeline Scores, Mean \pm SD $(95 \%$ CI $)$} & \multirow{3}{*}{$\begin{array}{l}\text { Between-Group } \\
\text { Differences, Mean }(95 \% \text { CI }\end{array}$} \\
\hline & \multicolumn{2}{|c|}{ Within-Group Change Scores, Mean (95\% CI) } & \\
\hline & $\mathrm{EX}+\mathrm{EDUC}$ & $\mathrm{EX}+\mathrm{EDUC}+\mathrm{MT}$ & \\
\hline \multicolumn{4}{|l|}{ Intensity of TMD Pain (NPRS, 0-10) } \\
\hline Baseline & $5.2 \pm 1.7(4.6$ to 5.8$)$ & $5.2 \pm 2.2(4.5$ to 5.9$)$ & \\
\hline After intervention & $4.1 \pm 1.2(3.6$ to 4.6$)$ & $3.2 \pm 1.8(2.7$ to 3.7$)$ & \\
\hline Change baseline $\rightarrow$ after intervention & $-1.1 \pm 1.0(-1.6$ to -0.6$)$ & $-2.0 \pm 1.8(-2.6$ to -1.4$)$ & $-0.9(-1.5 \text { to }-0.3)^{*}$ \\
\hline $3 \mathrm{mo}$ & $4.0 \pm 1.3(3.4$ to 4.6$)$ & $2.4 \pm 1.8(1.8$ to 3.0$)$ & \\
\hline Change baseline $\rightarrow 3$ mo & $-1.2 \pm 1.4(-1.9$ to -0.5$)$ & $-2.8 \pm 1.9(-3.5$ to -2.1$)$ & $-1.6(-2.5 \text { to }-0.7)^{*}$ \\
\hline $6 \mathrm{mo}$ & $3.6 \pm 1.5(3.0$ to 4.2$)$ & $2.2 \pm 1.5(1.6$ to 3.0$)$ & \\
\hline Change baseline $\rightarrow 6$ mo & $-1.6 \pm 1.5(-2.4$ to -0.8$)$ & $-3.0 \pm 1.8(-3.7$ to -2.3$)$ & $-1.4(-2.2 \text { to }-0.6)^{*}$ \\
\hline \multicolumn{4}{|l|}{ Tinnitus Severity (VAS, 0-10) } \\
\hline Baseline & $6.7 \pm 1.2(6.2$ to 7.2$)$ & $6.8 \pm 1.26 .3$ to 7.3$)$ & \\
\hline After intervention & $5.8 \pm 1.2(5.2$ to 6.4$)$ & $4.7 \pm 1.9(4.1$ to 5.3$)$ & \\
\hline Change baseline $\rightarrow$ after intervention & $-0.9 \pm 1.7(-1.5$ to -0.3$)$ & $-2.1 \pm 2.0(-2.9$ to -1.3$)$ & $-1.2(-2.0 \text { to }-0.4)^{*}$ \\
\hline $3 \mathrm{mo}$ & $5.2 \pm 1.5(4.6$ to 5.8$)$ & $3.6 \pm 1.7(3.0$ to 4.2$)$ & \\
\hline Change baseline $\rightarrow 3$ mo & $-1.5 \pm 1.9(-2.2$ to -0.8$)$ & $-3.2 \pm 2.0(-4.0$ to -2.4$)$ & $-1.7(-2.6 \text { to }-0.8)^{*}$ \\
\hline $6 \mathrm{mo}$ & $4.7 \pm 1.3(4.2$ to 5.2$)$ & $2.8 \pm 1.7(2.2$ to 3.4$)$ & \\
\hline Change baseline $\rightarrow 6$ mo & $-2.0 \pm 1.6(-2.6$ to -1.4$)$ & $-4.0 \pm 2.1(-4.7$ to -3.3$)$ & $-2.0(-3.6 \text { to }-1.0)^{*}$ \\
\hline \multicolumn{4}{|l|}{ Tinnitus Handicap Inventory $(0-100)$} \\
\hline Baseline & $34.2 \pm 11.9(30.2$ to 38.2$)$ & $36.1 \pm 9.6(32.2$ to 40.0$)$ & \\
\hline After intervention & $29.5 \pm 12.2(25.7$ to 33.3$)$ & $23.0 \pm 8.2(19.2$ to 26.8$)$ & \\
\hline Change baseline $\rightarrow$ after intervention & $-4.7 \pm 7.9(-7.6$ to -1.8$)$ & $-13.1 \pm 10.4(-16.9$ to -9.3$)$ & $-8.4(-12.8 \text { to }-4.0)^{*}$ \\
\hline $3 \mathrm{mo}$ & $28.8 \pm 12.3(25.1$ to 32.5$)$ & $17.1 \pm 7.5(13.4$ to 20.8$)$ & \\
\hline Change baseline $\rightarrow 3 \mathrm{mo}$ & $-5.4 \pm 8.1(-8.4$ to -2.4$)$ & $-19.0 \pm 9.8(-22.6$ to -15.4$)$ & $-13.6(-18.2 \text { to }-9.0)^{*}$ \\
\hline $6 \mathrm{mo}$ & $28.3 \pm 11.8(24.7$ to 31.9$)$ & $14.4 \pm 7.3(10.9$ to 17.9$)$ & \\
\hline Change baseline $\rightarrow 6$ mo & $-5.9 \pm 7.4(-8.6$ to -3.2$)$ & $-21.7 \pm 8.8(-25.0$ to -18.4$)$ & $-15.8(-19.6 \text { to }-12.0)^{*}$ \\
\hline
\end{tabular}

ANCOVA $=$ analysis of covariance; $\mathrm{CI}=$ confidence interval; EDUC = Education; EX= Exercise; $\mathrm{MT}=$ Manual therapy; NPRS = numeric pain rating scale $(0-$ 10 ; lower scores indicate less pain); TMD = temporomandibular disorder; TMJ = temporomandibular joint; VAS = visual analog scale (0-10; lower scores indicate less pain).

*Statistically significant differences between groups (ANCOVA, $P<0.001$ )

\section{Mandibular Range of Motion}

The ANCOVA revealed significant group * time interactions for changes in mandibular range of motion (mouth opening: $\mathrm{F}=17.683, P<0.001, \eta 2 \mathrm{p}=0.367$; lateral excursions: $F=18.594, P<0.001, \eta 2 p=0.395$ ): Patients receiving exercise/education plus manual therapy exhibited greater increases (large effect sizes) in mandibular range of motion than those receiving exercise and education alone (Table 4). Gender did not influence the interaction effects on maximum mouth opening $(\mathrm{F}=1.083, P=0.302)$ or lateral excursions $(\mathrm{F}=0.237$, $P=0.628)$.

\section{Pressure Pain Sensitivity}

The ANCOVA revealed significant group * time interactions for changes in PPTs in the masseter $(\mathrm{F}=29.494$, $P<0.001, \eta 2 \mathrm{p}=0.415)$, temporalis $(\mathrm{F}=18.594$, $P<0.001, \eta 2 \mathrm{p}=0.395)$, and the TMJ $(\mathrm{F}=15.448$, $P<0.001, \eta 2 \mathrm{p}=0.363$ ): Individuals receiving exercise/ education plus manual therapy showed greater increases (large effect sizes) in PPTs (decrease in pressure pain sensitivity) than those receiving exercise/education alone (Table 5). Gender did not influence the interaction effects on PPT (masseter: $\mathrm{F}=0.216, P=0.643$; temporalis: $\mathrm{F}=0.030, P=0.863$; TMJ area: $\mathrm{F}=0.214, P=0.646$ ).

\section{Discussion}

This randomized clinical trial found that inclusion of specific manual therapies targeting the TMJ and the cervical and masticatory musculature into a physical therapy program, including education and exercises, resulted in significantly better outcomes at three and six months than application of education and exercise alone in patients with somatic tinnitus attributed to TMD.

The Clinical Practice Guideline published by the American Academy of Otolaryngology-Head and Neck Surgery Foundation (AAO-HNSF) recommends education and cognitive behavior therapy for the management of tinnitus, but no recommendation of other therapeutic modalities is provided [39]. There is limited evidence for physiotherapy interventions and preliminary evidence for TMJ approaches in patients with somatic tinnitus $[11,12]$. This clinical trial is the first to add manual therapy targeting the TMJ and the cervical and masticatory muscles into a multimodal approach including exercise and education for patients with somatic tinnitus, 

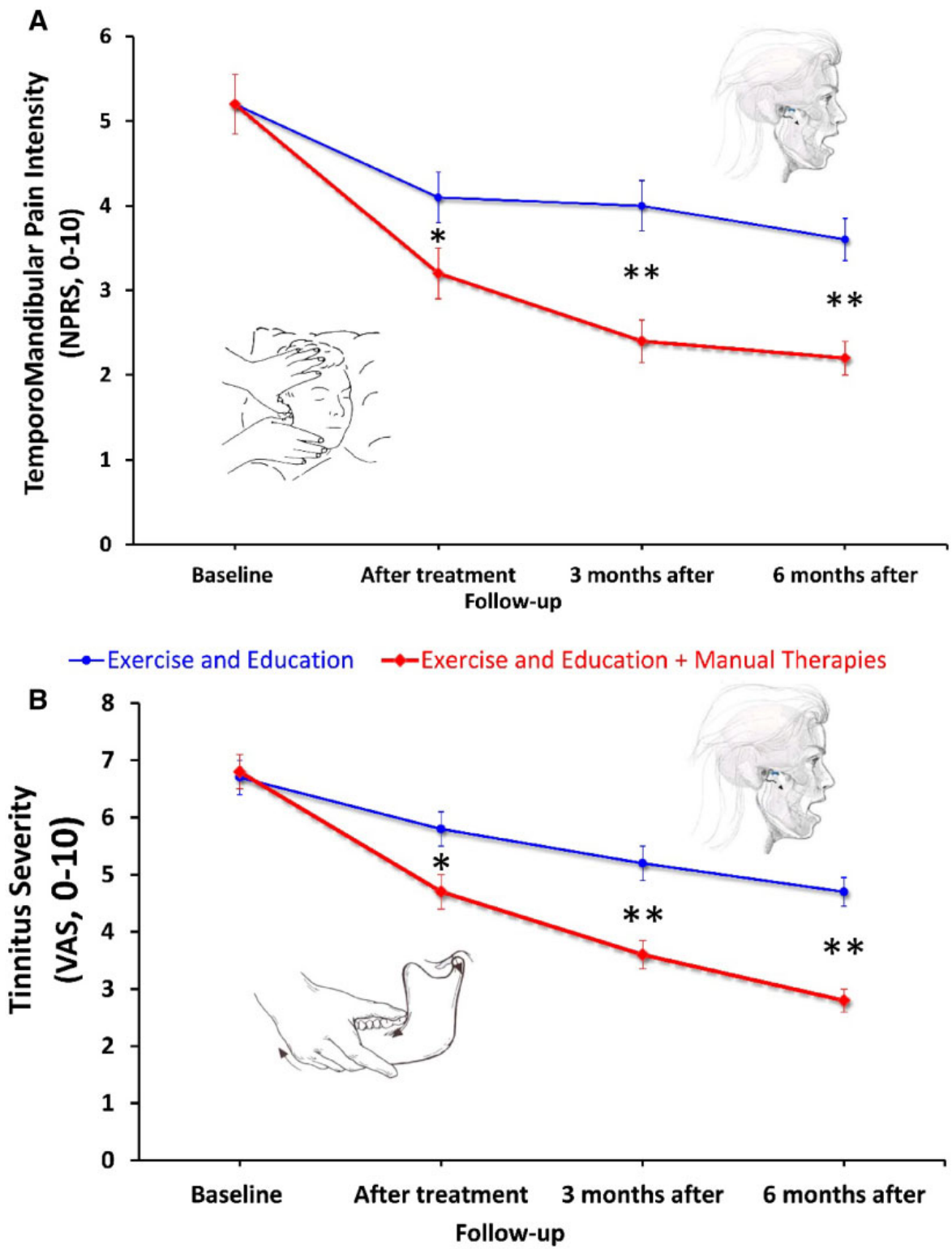

Figure 7. Evolution of temporomandibular pain intensity (A) and tinnitus severity (B) throughout the course of the study, stratified by randomized treatment assignment. Data are presented as mean (standard error). ${ }^{*} P<0.01 ;{ }^{*} P<0.001$.

reflecting common clinical practice. The results of our clinical trial found large effect sizes favoring the inclusion of cervico-mandibular manual therapy for the management of people with somatic tinnitus attributed to TMD; however, between-groups change scores did not surpass the MCID for each respective outcome. It should be noted that both groups showed significant within-group improvements in most outcomes, mostly at three and six months; nevertheless, only within-group change scores of the cervico-mandibular manual therapy group surpassed the MCID for most outcomes. Improvements in the physiotherapy group could be related to the fact that exercise and education have been found to be effective for the management of people with TMD symptoms $[9,10]$. Based on the current results, we could anticipate a potential clinical benefit of adding manual therapy targeting the TMJ and the cervical and masticatory musculature for patients with somatic tinnitus attributed to TMD; however, future trials are needed to clarify the clinical relevance of these therapeutic interventions.

Our results also showed that the inclusion of cervicomandibular manual therapies was able to induce better improvements in clinical (i.e., tinnitus-related handicap, TMD related-disability), psychological (i.e., depressive symptoms), and physical (i.e., mandibular active range of motion) outcomes, but not in health-related quality of life. These findings suggest that physical therapy approaches for patients with somatic tinnitus should be multimodal by including manual therapy, exercise, and education to facilitate multidimensional improvements in 
Table 3. Self-reported secondary outcomes at baseline, postintervention, three months, and six months after treatment, as well as within-group and between-groups mean scores by randomized treatment assignment

\begin{tabular}{|c|c|c|c|}
\hline \multirow[b]{3}{*}{ Outcomes } & \multicolumn{2}{|c|}{ Timeline Scores, Mean \pm SD $(95 \%$ CI $)$} & \multirow{3}{*}{$\begin{array}{l}\text { Between-Group Differences } \\
\text { Mean }(95 \% \text { CI })\end{array}$} \\
\hline & \multicolumn{2}{|c|}{ Within-Group Change Scores, Mean (95\% CI) } & \\
\hline & $\mathrm{EX}+\mathrm{EDUC}$ & $\mathrm{EX}+\mathrm{EDUC}+\mathrm{MT}$ & \\
\hline \multicolumn{4}{|c|}{ Craniofacial Pain and Disability Inventory $(0-63)$} \\
\hline Baseline & $38.6 \pm 5.5(6.1$ to 7.5$)$ & $40.7 \pm 8.2(38.2$ to 43.2$)$ & \\
\hline After intervention & $35.2 \pm 5.0(4.0$ to 5.6$)$ & $33.6 \pm 5.0(31.5$ to 35.7$)$ & \\
\hline Change baseline $\rightarrow$ after intervention & $-3.4 \pm 2.1(-4.2$ to -2.6$)$ & $-7.1 \pm 5.0(-9.0$ to -5.2$)$ & $-3.7(-5.7 \text { to }-1.7)^{*}$ \\
\hline $3 \mathrm{mo}$ & $34.0 \pm 5.4(4.1$ to 5.7$)$ & $29.8 \pm 5.8(27.8$ to 31.8$)$ & \\
\hline Change baseline $\rightarrow 3$ mo & $-4.6 \pm 2.8(-5.7$ to -3.5$)$ & $-10.9 \pm 5.9(-13.1$ to -8.7$)$ & $-6.3(-8.6 \text { to }-4.0)^{*}$ \\
\hline $6 \mathrm{mo}$ & $33.3 \pm 5.0(3.1$ to 5.1$)$ & $28.7 \pm 6.1$ (26.7 to 30.7$)$ & \\
\hline Change baseline $\rightarrow 6$ mo & $-5.3 \pm 2.4(-6.2$ to -4.4$)$ & $-12.0 \pm 5.0(-13.8$ to -10.2$)$ & $-6.7(-8.7 \text { to }-4.7)^{*}$ \\
\hline \multicolumn{4}{|l|}{ 12-Item Short Form Health Survey $(0-100)$} \\
\hline Baseline & $31.3 \pm 3.4(30.0$ to 32.6$)$ & $30.0 \pm 3.6(28.7$ to 31.3$)$ & \\
\hline After intervention & $31.9 \pm 2.2(30.8$ to 33.0$)$ & $30.0 \pm 3.4(28.8$ to 31.2$)$ & \\
\hline Change baseline $\rightarrow$ after intervention & $0.6 \pm 3.2(-0.6$ to 1.8$)$ & $0.0 \pm 3.1(-1.2$ to -1.2$)$ & $-0.6(-2.2$ to 1.0$)$ \\
\hline $3 \mathrm{mo}$ & $32.0 \pm 2.5(31.0$ to 33.0$)$ & $30.5 \pm 2.7(29.6$ to 31.4$)$ & \\
\hline Change baseline $\rightarrow 3$ mo & $0.7 \pm 3.5(-0.6$ to 2.0$)$ & $0.5 \pm 4.0(-1.0$ to 2.0$)$ & $-0.2(-2.0$ to 1.6$)$ \\
\hline $6 \mathrm{mo}$ & $31.9 \pm 2.8(30.9$ to 32.9$)$ & $30.9 \pm 2.4(29.9$ to 31.9$)$ & \\
\hline Change baseline $\rightarrow 6$ mo & $0.6 \pm 3.6(-0.7$ to 1.9$)$ & $0.9 \pm 3.9(-0.5$ to 2.3$)$ & $0.3(-1.5$ to 2.1$)$ \\
\hline \multicolumn{4}{|l|}{ Beck Depression Inventory (0-63) } \\
\hline Baseline & $6.5 \pm 7.3(4.2$ to 8.8$)$ & $7.4 \pm 5.4(5.1$ to 9.7$)$ & \\
\hline After intervention & $5.7 \pm 6.6(3.6$ to 7.8$)$ & $4.1 \pm 4.9(2.0$ to 6.2$)$ & \\
\hline Change baseline $\rightarrow$ after intervention & $-0.8 \pm 3.3(-2.0$ to 0.4$)$ & $-3.3 \pm 3.7(-4.7$ to -1.9$)$ & $-2.5(-4.0 \text { to }-1.0)^{*}$ \\
\hline $3 \mathrm{mo}$ & $6.3 \pm 7.0(4.2$ to 8.4$)$ & $3.1 \pm 4.6(1.0$ to 5.2$)$ & \\
\hline Change baseline $\rightarrow 3$ mo & $-0.2 \pm 5.2(-2.2$ to 1.8$)$ & $-4.3 \pm 3.4(-5.5$ to -3.1$)$ & $-4.1(-6.3 \text { to }-2.0)^{*}$ \\
\hline $6 \mathrm{mo}$ & $6.0 \pm 7.0(4.0$ to 8.0$)$ & $2.4 \pm 3.8(0.4$ to 4.4$)$ & \\
\hline Change baseline $\rightarrow 6$ mo & $-0.5 \pm 5.6(-2.5$ to 1.5$)$ & $-5.0 \pm 3.8(-6.4$ to -3.6$)$ & $-4.5(-7.0 \text { to }-2.0)^{*}$ \\
\hline
\end{tabular}

$\mathrm{ANCOVA}=$ analysis of covariance; $\mathrm{CI}=$ confidence interval; $\mathrm{EDUC}=$ Education; $\mathrm{EX}=$ Exercise; $\mathrm{MT}=$ Manual therapy

"Statistically significant differences between groups (ANCOVA, $P<0.001$ ).

Table 4. Mandibular range of motion at baseline, postintervention, three months, and six months after treatment, as well as withingroup and between-groups mean scores by randomized treatment assignment

\begin{tabular}{|c|c|c|c|}
\hline \multirow[b]{3}{*}{ Outcomes } & \multicolumn{2}{|c|}{ Timeline Scores, Mean \pm SD $(95 \%$ CI $)$} & \multirow{3}{*}{$\begin{array}{l}\text { Between-Group Differences } \\
\text { Mean }(95 \% \text { CI })\end{array}$} \\
\hline & \multicolumn{2}{|c|}{ Within-Group Change Scores, Mean (95\% CI) } & \\
\hline & $\mathrm{EX}+\mathrm{EDUC}$ & $\mathrm{EX}+\mathrm{EDUC}+\mathrm{MT}$ & \\
\hline \multicolumn{4}{|l|}{ Maximum Mouth Opening, $\mathrm{mm}$} \\
\hline Baseline & $31.5 \pm 3.2(30.5$ to 32.5$)$ & $30.5 \pm 3.2(29.0$ to 32.0$)$ & \\
\hline After intervention & $35.0 \pm 4.8(33.5$ to 36.5$)$ & $39.0 \pm 5.0(37.5$ to 40.5$)$ & \\
\hline Change baseline $\rightarrow$ after intervention & $3.5 \pm 2.7(2.2$ to 4.8$)$ & $8.5 \pm 4.5(7.3$ to 9.7$)$ & $5.0(3.8 \text { to } 6.2)^{*}$ \\
\hline $3 \mathrm{mo}$ & $36.0 \pm 4.1(34.5$ to 37.5$)$ & $41.0 \pm 4.5(39.5$ to 42.5$)$ & \\
\hline Change baseline $\rightarrow 3$ mo & $4.5 \pm 2.6(3.1$ to 5.9$)$ & $10.5 \pm 3.8(9.2$ to 11.8$)$ & $6.0(5.0 \text { to } 7.0)^{*}$ \\
\hline $6 \mathrm{mo}$ & $36.5 \pm 4.0(35.0$ to 38.0$)$ & $42.0 \pm 3.5(40.5$ to 43.5$)$ & \\
\hline Change baseline $\rightarrow 6$ mo & $5.0 \pm 2.9(3.6$ to 6.4$)$ & $11.5 \pm 3.3(10.7$ to 12.3$)$ & $6.5(5.0 \text { to } 8.0)^{*}$ \\
\hline \multicolumn{4}{|l|}{ Left Lateral Excursion, mm } \\
\hline Baseline & $5.9 \pm 0.7(5.5$ to 6.3$)$ & $5.8 \pm 0.8(5.4$ to 6.2$)$ & \\
\hline After intervention & $6.5 \pm 0.6(6.3$ to 6.7$)$ & $7.7 \pm 0.7(7.4$ to 8.0$)$ & \\
\hline Change baseline $\rightarrow$ after intervention & $0.6 \pm 0.8(0.3$ to 0.9$)$ & $1.9 \pm 1.0(1.6$ to 2.2$)$ & $1.3(1.0 \text { to } 1.6)^{*}$ \\
\hline $3 \mathrm{mo}$ & $7.0 \pm 0.8(6.6$ to 7.4$)$ & $8.4 \pm 0.8(8.0$ to 8.8$)$ & \\
\hline Change baseline $\rightarrow 3$ mo & $1.1 \pm 1.0(0.7$ to 1.5$)$ & $2.6 \pm 0.9(2.3$ to 2.9$)$ & $1.5(1.1 \text { to } 2 \text { to } 9)^{*}$ \\
\hline $6 \mathrm{mo}$ & $7.2 \pm 1.1(6.7$ to 8.2$)$ & $9.0 \pm 0.8(8.5$ to 9.5$)$ & \\
\hline Change baseline $\rightarrow 6$ mo & $1.3 \pm 1.1(1.0$ to 1.6$)$ & $3.2 \pm 0.7(3.0$ to 3.4$)$ & $1.9(1.4 \text { to } 2.3)^{*}$ \\
\hline \multicolumn{4}{|l|}{ Right Lateral Excursion, mm } \\
\hline Baseline & $5.9 \pm 0.6(5.7$ to 6.1$)$ & $5.7 \pm 0.7(5.5$ to 5.9$)$ & \\
\hline After intervention & $6.6 \pm 0.7(6.3$ to 6.9$)$ & $7.7 \pm 0.9(7.3$ to 8.1$)$ & \\
\hline Change baseline $\rightarrow$ after intervention & $0.7 \pm 0.8(0.4$ to 1.0$)$ & $2.0 \pm 1.1(1.5$ to 2.5$)$ & $1.3(0.9 \text { to } 1.7)^{*}$ \\
\hline $3 \mathrm{mo}$ & $7.0 \pm 0.7(6.6$ to 7.4$)$ & $8.6 \pm 1.1(8.3$ to 8.9$)$ & \\
\hline Change baseline $\rightarrow 3 \mathrm{mo}$ & $1.1 \pm 1.0(0.7$ to 1.5$)$ & $2.9 \pm 1.2(2.4$ to 3.4$)$ & $1.8(1.3 \text { to } 2.3)^{*}$ \\
\hline $6 \mathrm{mo}$ & $7.2 \pm 0.8(6.8$ to 7.6$)$ & $9.2 \pm 1.0(8.7$ to 9.7$)$ & \\
\hline Change baseline $\rightarrow 6$ mo & $1.3 \pm 1.0(0.9$ to 1.7$)$ & $3.5 \pm 1.3(2.9$ to 4.1$)$ & $2.2(1.6 \text { to } 2.8)^{*}$ \\
\hline
\end{tabular}

$\mathrm{ANCOVA}=$ analysis of covariance; $\mathrm{CI}=$ confidence interval; $\mathrm{EDUC}=$ Education; $\mathrm{EX}=$ Exercise; $\mathrm{MT}=$ Manual therapy.

*Statistically significant differences between groups (ANCOVA, $P<0.001$ ). 
Table 5. Pressure pain thresholds $\left(\mathrm{kg} / \mathrm{cm}^{2}\right)$ at baseline, postintervention, three months, and six months after treatment, as well as within-group and between-groups mean scores by randomized treatment assignment

\begin{tabular}{|c|c|c|c|}
\hline \multirow[b]{3}{*}{ Outcomes } & \multicolumn{2}{|c|}{ Timeline Scores, Mean \pm SD $(95 \%$ CI $)$} & \multirow{3}{*}{$\begin{array}{l}\text { Between-Group Differences, } \\
\text { Mean }(95 \% \text { CI })\end{array}$} \\
\hline & \multicolumn{2}{|c|}{ Within-Group Change Scores, Mean (95\% CI) } & \\
\hline & $\mathrm{EX}+\mathrm{EDUC}$ & $\mathrm{EX}+\mathrm{EDUC}+\mathrm{MT}$ & \\
\hline \multicolumn{4}{|c|}{ Pressure Pain Thresholds over the Masseter Muscle, $\mathrm{kg} / \mathrm{cm}^{2}$} \\
\hline Baseline & $2.2 \pm 0.4(2.0$ to 2.4$)$ & $2.1 \pm 0.2(2.0$ to 2.2$)$ & \\
\hline After intervention & $2.3 \pm 0.5(2.1$ to 2.5$)$ & $2.6 \pm 0.4(2.4$ to 2.8$)$ & \\
\hline Change baseline $\rightarrow$ after intervention & $0.1 \pm 0.2(0.0$ to 0.2$)$ & $0.5 \pm 0.3(0.3$ to 0.7$)$ & $0.4(0.2 \text { to } 0.6)^{*}$ \\
\hline $3 \mathrm{mo}$ & $2.4 \pm 0.4(2.2$ to 2.6$)$ & $2.8 \pm 0.3(2.6$ to 3.0$)$ & \\
\hline Change baseline $\rightarrow 3$ mo & $0.2 \pm 0.2(0$ to 1 to 0.3$)$ & $0.7 \pm 0.4(0.5$ to 0.9$)$ & $0.5(0.3 \text { to } 0.7)^{*}$ \\
\hline $6 \mathrm{mo}$ & $2.5 \pm 0.4(2.3$ to 2.7$)$ & $2.9 \pm 0.3(2.7$ to 3.1$)$ & \\
\hline Change baseline $\rightarrow 6$ mo & $0.3 \pm 0.2(0.2$ to 0.4$)$ & $0.8 \pm 0.4(0.6$ to 1.0$)$ & $0.5(0.4 \text { to } 0.6)^{*}$ \\
\hline \multicolumn{4}{|c|}{ Pressure Pain Thresholds over the Temporalis Muscle, $\mathrm{kg} / \mathrm{cm}^{2}$} \\
\hline Baseline & $2.3 \pm 0.4(2.1$ to 2.5$)$ & $2.2 \pm 0.3(2.0$ to 2.4$)$ & \\
\hline After intervention & $2.5 \pm 0.4(2.3$ to 2.7$)$ & $2.6 \pm 0.3(2.4$ to 2.8$)$ & \\
\hline Change baseline $\rightarrow$ after intervention & $0.2 \pm 0.2(0.1$ to 0.3$)$ & $0.4 \pm 0.2(0.3$ to 0.5$)$ & $0.2(0.1 \text { to } 0.3)^{*}$ \\
\hline $3 \mathrm{mo}$ & $2.6 \pm 0.4(2.4$ to 2.8$)$ & $2.8 \pm 0.3(2.6$ to 3.0$)$ & \\
\hline Change baseline $\rightarrow 3$ mo & $0.3 \pm 0.3(0.1$ to 0.5$)$ & $0.6 \pm 0.2(0.5$ to 0.7$)$ & $0.3(0.2 \text { to } 0.4)^{*}$ \\
\hline $6 \mathrm{mo}$ & $2.6 \pm 0.4(2.4$ to 2.8$)$ & $2.9 \pm 0.3(2.7$ to 3.1$)$ & \\
\hline Change baseline $\rightarrow 6$ mo & $0.3 \pm 0.3(0.1$ to 0.5$)$ & $0.7 \pm 0.2(0.6$ to 0.8$)$ & $0.4(0.2 \text { to } 0.6)^{*}$ \\
\hline \multicolumn{4}{|c|}{ Pressure Pain Thresholds over the Lateral Aspect of the TMJ, $\mathrm{kg} / \mathrm{cm}^{2}$} \\
\hline Baseline & $2.2 \pm 0.4(2.0$ to 2.4$)$ & $2.3 \pm 0.4(2.1$ to 2.5$)$ & \\
\hline After intervention & $2.4 \pm 0.4(2.2$ to 2.6$)$ & $2.6 \pm 0.3(2.4$ to 2.8$)$ & \\
\hline Change baseline $\rightarrow$ after intervention & $0.2 \pm 0.3(0.0$ to 0.4$)$ & $0.3 \pm 0.3(0.1$ to 0.5$)$ & $0.1(0.0$ to 0.2$)$ \\
\hline $3 \mathrm{mo}$ & $2.5 \pm 0.4(2.3$ to 2.7$)$ & $2.8 \pm 0.3(2.6$ to 3.0$)$ & \\
\hline Change baseline $\rightarrow 3$ mo & $0.3 \pm 0.3(0.1$ to 0.5$)$ & $0.5 \pm 0.3(0.3$ to 0.5$)$ & $0.2(0.1 \text { to } 0.3)^{*}$ \\
\hline $6 \mathrm{mo}$ & $2.6 \pm 0.4(2.4$ to 2.8$)$ & $2.9 \pm 0.3(2.7$ to 3.1$)$ & \\
\hline Change baseline $\rightarrow 6$ mo & $0.4 \pm 0.3(0.2$ to 0.6$)$ & $0.6 \pm 0.3(0.4$ to 0.8$)$ & $0.2(0.1 \text { to } 0.3)^{*}$ \\
\hline
\end{tabular}

ANCOVA = analysis of covariance; $\mathrm{CI}=$ confidence interval; EDUC = Education; EX = Exercise; MT = Manual therapy; NPRS = numeric pain rating scale (0-10; lower scores indicate less pain); TMJ = temporomandibular joint; VAS = visual analog scale (0-10; lower scores indicate less pain).

*Statistically significant differences between groups (ANCOVA, $P<0.001$ ).

this population. We also observed a localized hypoalgesic effect, as expressed by an increase in PPTs, in both groups, particularly within the manual therapy group. There is evidence supporting that manual therapy is able to increase PPTs in individuals with musculoskeletal pain [40]. These results confirm the neuro-physiological effects of manual therapy and exercise within the central nervous system, as previously suggested [41]. Nevertheless, although changes were superior in individuals receiving manual therapy, between-group differences were small, and clinical relevance remains unclear.

The results of this clinical trial would suggest a correlation between TMD and tinnitus in our sample, as appropriate TMD treatment improved the severity and distress of the tinnitus. The mechanisms linking TMD and tinnitus remain to be further elucidated, and anatomical and physiological theories are currently proposed. For instance, the anatomical relationship between TMJ ligaments and muscles and the inner ear provides a hypothesis regarding where movements of the mandibular condyle producing tension in these structures can result in self-perceived tinnitus. Additionally, different animal studies have described connections between the somatosensory system of the cervical spine and the TMJ and the cochlear nuclei of the ear [42]. Shore et al. [43] showed that the trigeminal and dorsal root ganglia relay afferent somatosensory information from the periphery to secondary sensory neurons within the brain stem, specifically the spinal trigeminal nucleus and dorsal column nuclei, respectively. These physiological links explain that the musculoskeletal somatosensory system of the cervical musculature and TMJ is able to influence the auditory system by altering spontaneous rates (i.e., not driven by auditory stimuli). Any of these hypotheses would explain the results of the current clinical trial, yet they require further scientific evaluation.

The results of this multicenter randomized clinical trial should be considered according to its potential strengths and limitations. Major strengths are the inclusion of patients with defined somatic tinnitus, concealed allocation, a best-evidence multimodal approach treatment including exercise and education, blinded outcome assessments, intention-to-treat analysis, and a six-month follow-up period. Among the limitations, first, as there is no objective method for the diagnosis of tinnitus, this is a self-reported diagnosis; therefore, current data should be not extrapolated to different subgroups of patients. Second, we did not include a control group without application of any intervention, so we do not know the natural course of the disease. It is important to note that 
TMDs are often self-limited over time, and significant fluctuation of the symptoms can be observed [44,45]; therefore, we cannot determine if the changes observed in both groups can be specifically attributed to interventions or simply the passage of time. Future clinical trials should include a real control group that does not receive any intervention to determine the real effects of the therapy. Third, the influence of the placebo effect is unknown, as we did not include a group receiving a sham manual therapy approach. We do not know if the facts that patients within the manual therapy group received manual contact and that the clinician spent slightly more time with them could have had a powerful benefit and whether they could have produced the difference between groups. In addition, although we tried to blind patients, it is possible that individuals' expectations for manual contact may also have had an impact on the results. Future trials including a control/sham group should be conducted to determine the best therapeutic option for somatic tinnitus attributed to TMD. Finally, subgroups of patients who would benefit most from these interventions and factors associated with successful treatment in either management approach should be elucidated in future trials.

\section{Conclusions}

The inclusion of manual therapies targeting the TMJ and the cervical and masticatory musculature into a multimodal physical therapy program including education and exercise resulted in significantly better clinical, psychological, and physical outcomes at three and six months than the application of education and exercise alone in a sample of patients with somatic tinnitus attributed to TMD.

\section{Authors' Contributions}

All authors contributed to the study concept and design. CFdlP, JC, and MJDA did the main statistical analysis and interpretation of data. GPM, CFdlP, and JC contributed to drafting the report. GPM, PMC, and MJDA provided administrative, technical, and material support. PMC and MJDA supervised the study. All authors revised the text for content and have read and approved the final version of the manuscript.

\section{References}

1. Harrison AL, Thorp JN, Ritzline PD. A proposed diagnostic classification of patients with temporomandibular disorders: Implications for physical therapists. J Orthop Sports Phys Ther 2014;44 (3):182-97.

2. Nassif NJ, Al-Salleeh F, Al-Admawi M. The prevalence and treatment need of symptoms and signs of temporomandibular disorders among young adult males. J Oral Rehabil 2003;30(9):944-50.
3. Köhler AA, Hugoson A, Magnusson T. Clinical signs indicative of temporomandibular disorders in adults: Time trends and associated factors. Swed Dent J 2013;37(1):1-11.

4. Joury E, Bernabe E, Gallagher JE, Marcenes W. Burden of orofacial pain in a socially deprived and culturally diverse area of the United Kingdom. Pain 2018;159(7):1235-124.

5. Baguley D, McFerran D, Hall D. Tinnitus. Lancet 2013;382(9904):1600-7.

6. Algieri GMA, Leonardi A, Arangio P, Vellone V, Paolo CD, Cascone P. Tinnitus in temporomandibular joint disorders: Is it a specific somatosensory tinnitus subtype? Int Tinnitus J 2017;20(2):83-7.

7. Kim YH, Park YG, Han KD, Vu D, Cho KH, Lee SY. Prevalence of tinnitus according to temporomandibular joint disorders and dental pain: The Korean National Population-based Study. J Oral Rehabil 2018;45(3):198-203.

8. Song HS, Shin JS, Lee J, et al. Association between temporomandibular disorders, chronic diseases, and ophthalmologic and otolaryngologic disorders in Korean adults: A cross-sectional study. PLoS One 2018;13(1):e0191336.

9. Dickerson SM, Weaver JM, Boyson AN, et al. The effectiveness of exercise therapy for temporomandibular dysfunction: A systematic review and meta-analysis. Clin Rehabil 2017;31(8):1039-48.

10. Armijo-Olivo S, Pitance L, Singh V, Neto F, Thie N, Michelotti A. Effectiveness of manual therapy and therapeutic exercise for temporomandibular disorders: Systematic review and meta-analysis. Phys Ther 2016;96(1):9-25.

11. Michiels S, Naessens S, Van de Heyning P, et al. The effect of physical therapy treatment in patients with subjective tinnitus: A systematic review. Front Neurosci 2016;10:545.

12. Buergers R, Kleinjung T, Behr M, Vielsmeier V. Is there a link between tinnitus and temporomandibular disorders? J Prosthet Dent 2014;111(3):222-7.

13. Zwarenstein $M$, Treweek S, Gagnier JJ, et al; CONSORT Group; Pragmatic Trials in Healthcare (Practihc) Group. Improving the reporting of pragmatic trials: An extension of the CONSORT statement. BMJ 2008;337:a2390.

14. Dworkin SF, LeResche L. Research diagnostic criteria for temporomandibular disorders: Review, criteria, examinations and specifications, critique. J Craniomandib Disord 1992;6(4):301-55.

15. Sanchez TG, Rocha CB. Diagnosis and management of somatosensory tinnitus: Review article. Clinics 2011;66(6):1089-94.

16. Durham J, Al-Baghdadi M, Baad-Hansen L, et al. Self-management programs in temporomandibular disorders: Results from an international Delphi process. J Oral Rehabil 2016;43 (12):929-36. 
17. Simons DG, Travell J, Simons LS. Myofascial Pain and Dysfunction: The Trigger Point Manual. 3rd ed. Philadelphia, PA: Wolters Kluwer; 2019.

18. Rocha C, Sanchez T. Efficacy of myofascial trigger point deactivation for tinnitus control. Braz J Otorhinolaryngol 2012;78(6):21-6.

19. Teachey WS, Wijtmans EH, Cardarelli F, Levine RA. Tinnitus of myofascial origin. Int Tinnitus J 2012;17 (1):70-3.

20. Jensen MP, Turner JA, Romano JM, Fisher LD. Comparative reliability and validity of chronic pain intensity measures. Pain 1999;83(2):157-62.

21. Farrar J, Young JJ, La Moreaux L, Werth JL, Poole RM. Clinical importance of changes in chronic pain intensity measured on an 11-pont numerical pain rating scale. Pain 2001;94(2):149-58.

22. Dworkin RH, Turk DC, McDermott MP, et al. Interpreting the clinical importance of group differences in chronic pain clinical trials: IMMPACT recommendations. Pain 2009;146(3):238-44.

23. Adamchic I, Langguth B, Hauptmann C, Tass PA. Psychometric evaluation of visual analog scale for the assessment of chronic tinnitus. Am J Audiol 2012;21 (2):215-25.

24. Newman CW, Jacobson GP, Spitzer JB. Development of the Tinnitus Handicap Inventory. Arch Otolaryngol 1996;122(2):143-8.

25. La Touche R, Pardo-Montero J, Gil-Martínez A, et al. Craniofacial Pain and Disability Inventory (CF-PDI): Development and psychometric validation of a new questionnaire. Pain Physician 2014;17(1):95-108.

26. Ware J Jr, Kosinski M, Keller SD. A 12-item ShortForm Health Survey: Construction of scales and preliminary tests of reliability and validity. Med Care 1996;34(3):220-33.

27. Beck AT, Steer RA, Brown GK. Beck Depression Inventory. 2nd ed. San Antonio, TX: The Psychological Corporation; 1996.

28. Kleinstäuber M, Frank I, Weise C. A confirmatory factor analytic validation of the Tinnitus Handicap Inventory. J Psychosom Res 2015;78(3):277-84.

29. Baguley DM, Andersson G. Factor analysis of the Tinnitus Handicap Inventory. Am J Audiol 2003;12 (1):31-4.

30. Fackrell K, Hall DA, Barry J, Hoare DJ. Tools for tinnitus measurement: Development and validity of questionnaires to assess handicap and treatment effects. In: Signorelli F, Turjman F, eds. Tinnitus: Causes Treatment and Short \& Long-Term Health Effects. New York: Nova Science Publishers Inc.; 2014:13-60.

31. Wang YP, Gorenstein C. Assessment of depression in medical patients: A systematic review of the utility of the Beck Depression Inventory-II. Clinics 2013;68 (9):1274-87.
32. Vanderweeën L, Oostendorp RA, Vaes P, Duquet W. Pressure algometry in manual therapy. Man Ther 1996;1(5):258-65.

33. Isselèe $H$, De Laat A, Lesaffre E, Lysens R. Short-term reproducibility of pressure pain thresholds in masseter and temporalis muscles of symptom-free subjects. Eur J Oral Sci 1997;105:583-7.

34. Gomes MB, Guimarães JP, Guimarães FC, Neves AC. Palpation and pressure pain threshold: Reliability and validity in patients with temporomandibular disorders. Cranio 2008;26(3):202-10.

35. Beltran-Alacreu H, Lopez-de-Uralde-Villanueva I, Paris-Alemany A, Angulo-Díaz-Parreño S, La Touche R. Intra-rater and inter-rater reliability of mandibular range of motion measures considering a neutral craniocervical position. J Phys Ther Sci 2014;26 (6):915-20.

36. Kropmans T, Dijkstra P, Stegenga B, Stewart R, de Bont L. Smallest detectable difference of maximal mouth opening in patients with painfully restricted temporomandibular joint function. Eur J Oral Sci 2000;108(1):9-13.

37. Carlesso LC, Macdermid JC, Santaguida L. Standardization of adverse event terminology and reporting in orthopaedic physical therapy: Application to the cervical spine. J Orthop Sports Phys Ther 2010;40(8):455-63.

38. Gray CD, Kinnear PR. IBM SPSS Statistics 19. London: Psychology Press; 2012.

39. Tunkel DE, Bauer CA, Sun GH, et al. Clinical practice guideline: Tinnitus. Otolaryngol Head Neck Surg 2014;151(2_Suppl):S1-40.

40. Voogt L, de Vries J, Meeus M, Struyf F, Meuffels D, Nijs J. Analgesic effects of manual therapy in patients with musculoskeletal pain: A systematic review. Man Ther 2015;20(2):250-6.

41. Bialosky JE, Beneciuk JM, Bishop MD, et al. Unraveling the mechanisms of manual therapy: Modeling an approach. J Orthop Sports Phys Ther 2018;48(1):8-18.

42. Zhan X, Pongstaporn T, Ryugo DK. Projections of the second cervical dorsal root ganglion to the cochlear nucleus in rats. J Comp Neurol 2006;496 (3):335-48.

43. Shore S, Zhou J, Koehler S. Neural mechanisms underlying somatic tinnitus. Prog Brain Res 2007;166: 107-23.

44. Melis M, Di Giosia M, Colloca L. Ancillary factors in the treatment of orofacial pain: A topical narrative review. J Oral Rehabil 2019;46(2):200-20.

45. Fillingim RB, Slade GD, Greenspan JD, et al. Longterm changes in biopsychosocial characteristics related to temporomandibular disorder: Findings from the OPPERA study. Pain 2018;159(11):2403-13. 